\title{
Radiographic Imaging Assessment Prior to Implant Placement - Choice of Dentists in Nagpur City
}

\author{
Akhilesh Shewale, Deepti Gattani, Bhagyashree Gudadhe, Sneha Meshram \\ Department of Periodontology, Swargiya Dadasaheb Kalmegh Smruti Dental College and Hospital, Nagpur, Maharashtra, India
}

Email for correspondence: akhileshshewale@gmail.com

\begin{abstract}
Background: In the present era, implant dentistry has seen exponential growth, and its success mainly depends on a proper treatment planning and its execution. Radiographic imaging has a pivotal role in the planning of implant placement and to keep the check on implant survival. Aims and Objectives: The aim of this study is to survey the radiographic prescription trends among the dental practitioners. Materials and Methods: A survey questionnaire was prepared by an expert panel consisting of 5 academicians from the field of implantology. This questionnaire was then distributed among 175 dentists practising in Nagpur, India. The data collected from the survey were analyzed using Epi Info version 7.1.3 software. Results: Within the limitation of the study, it was observed that the majority of dentists sampled prescribe panoramic radiographs for dental implant assessment based on its availability. Conclusion: The majority of dentists prescribed panoramic radiographs for dental implant assessment based on its availability, and only a small number strictly adhered to the recommended guidelines of the world associations with regard to cross-sectional imaging.
\end{abstract}

Key words: Impants, radiographs, survey

\section{INTRODUCTION}

Implant dentistry has experienced a giant stride today. Dental implants have been widely used for the replacement of edentulous spaces, and with evergrowing innovative technical advances in this field, its usage by the practitioners has been speed up at precipitous speeds. The way dental practitioners have taken up this treatment modality and adapted to the advancements in oral rehabilitation is really remarkable. The main criteria in assessing the success of oral implants have been the marginal bone loss evidenced by the radiological examination. ${ }^{[1-3]}$ The imaging objectives aid the clinician in providing

\begin{tabular}{|l|l|}
\hline Quick Response Code & Article Info: \\
\hline doi: 10.5866/2017.9.10139 \\
\hline $\begin{array}{l}\text { Received: 04-08-2017 } \\
\text { Revised: } 10-09-2017 \\
\text { Accepted: 18-09-2017 } \\
\text { Available Online: } 27-11-2017 \text { (www.nacd. } \\
\text { in)@ NAD, } 2017 \text { - All rights reserved }\end{array}$ \\
\hline
\end{tabular}

the cross-sectional views of the dental arch for visualization of spatial relationship of anatomic structures of the maxilla and mandible, the quality and quantity of available bone, the presence of infrabony lesions, the occlusal pattern, and the number and size of implants as well as prosthesis design, all which are essential for successful implant treatment planning and evaluation of the ongoing implant functioning. ${ }^{[4]}$ Many types of radiographic modalities are used in implantology, namely, i.e., intraoral periapical radiography (IOPAR), orthopantomography (OPG), occlusal radiography, conventional tomography, computed tomography (CT), and cone-beam CT (CBCT). Usually, it is up to the practising clinician who decides which modality best suits their needs. ${ }^{[5-7]}$ The recent position paper on the use of radiology in dental implantology put forward by the American Academy of Oral and Maxillofacial Radiology (AAOMR) recommended that cross-sectional imaging be used for the assessment of all dental implant sites and that currently CBCT is the imaging method of choice at present to gain this diagnostic information. ${ }^{[8]}$ 
There is an extreme scarcity worldwide regarding the literature stating the radiographic prescription trends among the implant practitioners worldwide and whether they adhere to the recommendations put forward by professional bodies sch as the AAOMR, European Academy of Dentomaxillofacial Radiology, European Association of Osseointegration, and International Congress of Oral Implantology. ${ }^{[9]}$ Hence, looking at the need of the hour, an attempt was made to survey the radiographic prescription trends among the dental practitioners.

\section{MATERIALS AND METHODS}

A survey questionnaire was prepared by an expert panel consisting of 5 academicians from the field of implantology and having a vast experience of more than 10 years. This questionnaire was then distributed among 175 dentists practising in Nagpur, India. Of 175, 150 dentists (86 male and 64 female) volunteered to participate in the survey, and they were assured about the confidentiality of their identities. The questionnaire was formatted in a way to enquire about their radiographic prescription methods for pre- and post-operative assessment in their implantology practice and data collected regarding the radiographic prescription practices for pre-operative implant assessment and follow-up, such as panaromic radiograph (OPG), IOPAR, and CT or combination of any among these. The questionnaire also enquired about the inspiring factors for choosing the radiographic examination. The problems of over or underestimating measurement in panoramic X-ray and its frequency and usage of CT for implant imaging were also included in this survey. They were also enquired about their frequency and usage of the periapical radiograph. The data collected from the survey were analyzed using Epi Info version 7.1.3 software. Chi-square test was applied, and the results were determined at $P<0.05$ and confidence interval of $95 \%$.

\section{RESULTS}

The survey was carried out on 150 dentists having a clinical experience of more than 10 years $(17.50 \%), 6-10$ years $(76 \%)$, and $1-5$ years $(6.50 \%)$. The gender-wise distribution of radiographic examinations more often prescribed for dental implant assessment was shown in Graph 1. Approximately, 59\% of dentist prescribes panoramic $\mathrm{X}$-ray, whereas $41 \%$ of dentist prescribes a combination of panoramic X-ray + CT imaging. No

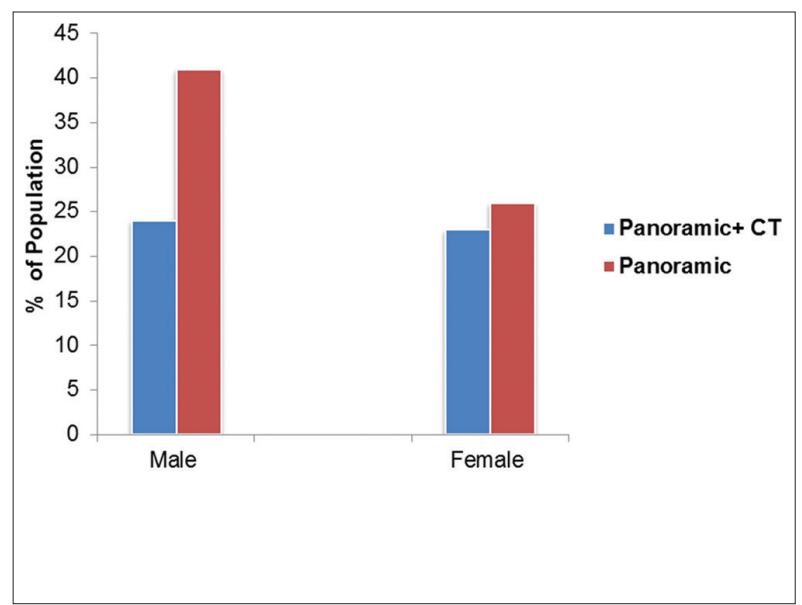

Graph 1: The gender-wise distribution of radiographic examinations more often prescribed for dental implant assessment

statistical significance difference exists among the genders in terms of their radiographic prescription pattern $(P>0.05)$. The gender- and experiencewise data of motivating factors for prescribing the specific radiologic examination were observed to be in following order:

Availability $>$ availability + cost $>$ cost + measurement precision $>$ cost + radiation dose $>$ measurement precision [Graph 2]. No statistical significant difference existed among the gender and years of experience.

Dentists prescribing CT imaging were found be $47 \%$. No significant difference existed among the gender in terms of using CT $(P>0.05)$ [Graph 3]. $76 \%$ of the participants and their gender-wise distribution of IOPA usage was given in Graph 4.

\section{DISCUSSION}

The main objective to survey the current radiographic prescription in dental implant assessment was to determine the prescription pattern among the experienced dentists and whether dentists are using imaging modalities for implant placement as recommended by the AAOMR. In the present study, the panoramic radiograph was the most frequent radiographic examination prescribed for treatment planning of osseointegrated implants. Approximately, 59\% of dentists prescribed the panoramic radiograph, as a single examination technique, and $41 \%$ of dentists combined it with a CT examination. The results of this study were in agreement with those obtained 


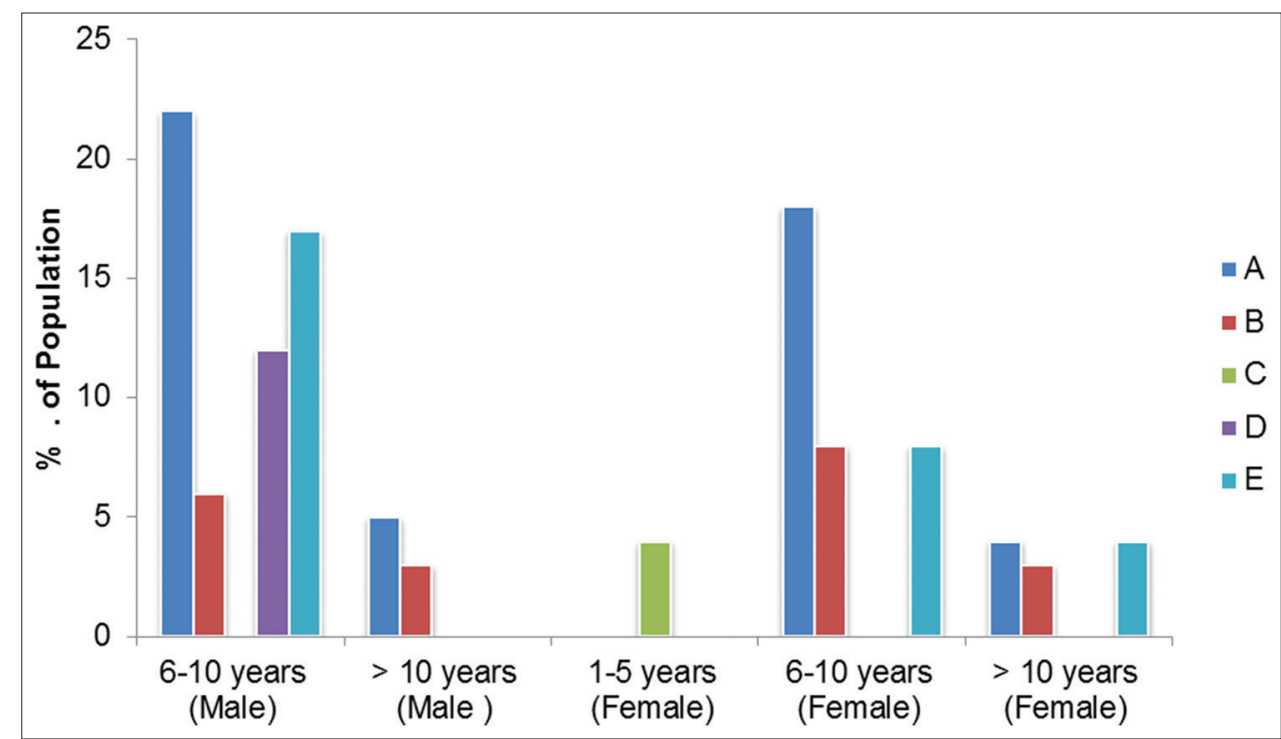

Graph 2: Gender and experience-wise distribution of motivating factors for prescribing the specific radiologic examination. A: Availability, B: Availability + cost , C: Cost + measurement precision, D: Cost + radiation dose, E: Measurement precision

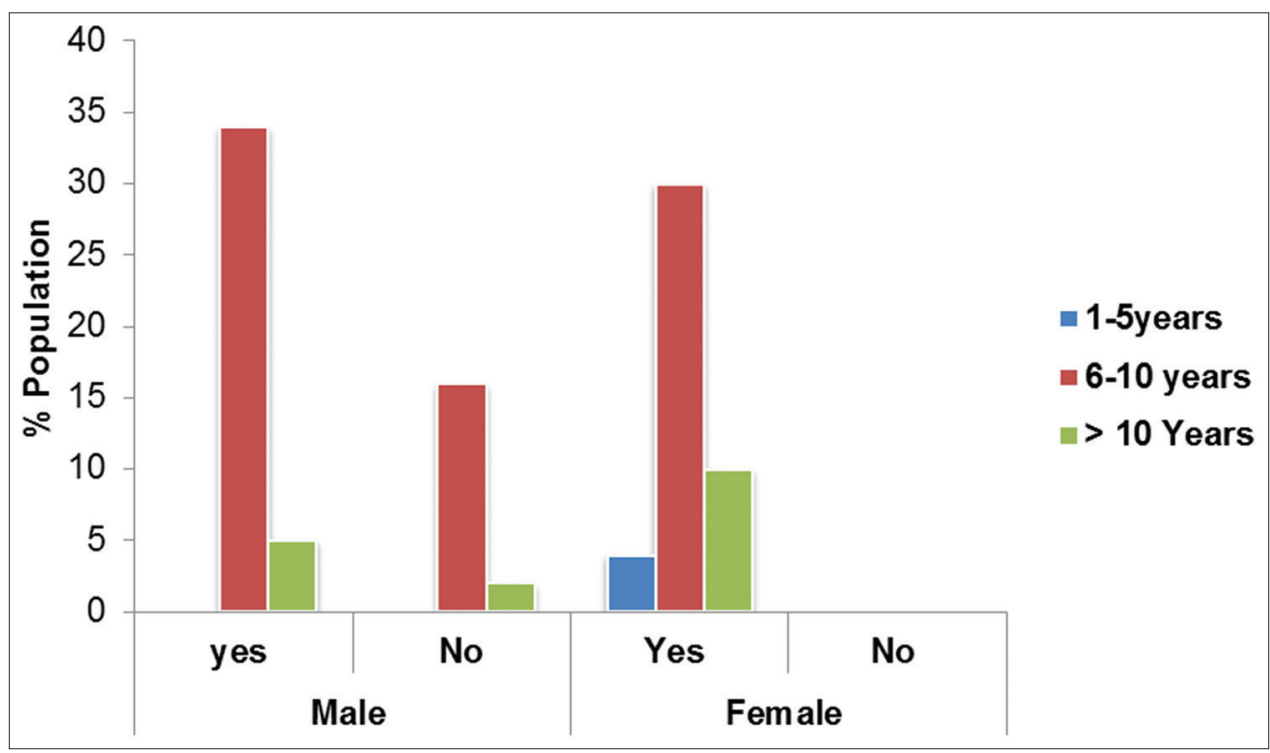

Graph 3: Gender and experience-wise \% population using computed tomography

by Beason and Brooks ${ }^{[10]}$ in Michigan Dentists and Ramakrishnan ${ }^{[11]}$ in Kerala Dentists.

In the present study, it was found that majority of the dentists prescribed the radiographic imaging modality based on its availability. The reason of prescribing OPG could be the availability of dentofacial imaging centers past in and around Nagpur, where many new centers mushroomed during the past decade. The findings of the present study were again in favor of the study by
Ramakrishnan, who also observed availability as the main driving tool in prescribing the imaging technique.

The present study also interviewed the \% of dentists using periapical radiographs and its reason. It was found that only a small percentage of dentists use it during surgery and follow-up, whereas themajority of them tends to avoid it. Peñarrocha et al. suggested that conventional periapical radiographs and digital radiographs were 
more accurate than panoramic radiographs in the assessment of peri-implant bone loss. ${ }^{[12]}$ Periapical radiographs require less radiation dose and produces minimal magnification and a minimally distorted relationship between the bone height and adjacent teeth, making it a more convenient diagnostic tool in clinical practice. ${ }^{[8]}$ However, it was underlooked by most of the dentists in the present study.

The panoramic radiograph gives useful information in the initial evaluation for preoperative planning but owing to its large horizontal magnification varying region wise. Another limitation is the lack of information in the third dimension. ${ }^{[6-8]}$ An important aspect to be considered in the implant imaging prescription is the radiation dose. However, in the present study, only $11 \%$ dentists looked on this reason for prescribing radiologic examination and the most observed reason for choosing the radiologic examination was its availability following by the measurement precision. This results are in consistent with that the results obtained by the study of Majid et al. ${ }^{[13]}$ Although panoramic radiograph requires only a small radiation dose, it does not provide information in the third dimension, which is considered necessary by some. Following the as low as reasonably achievable principle, for cross-sectional imaging, the AAOMR recommends conventional tomography for one to seven implant sites and CT for eight or more implant sites. ${ }^{[8]}$

When comparing the frequency of over- and under-estimated measurements of panoramic radiography, it was found that $50 \%$ of dentists tend to underestimate and $34 \%$ of dentist overestimate the measurement [Table 1]. This fact can be explained by the presence of different levels of magnification and distortion related to anatomical regions and lack of cross-sectional images. ${ }^{[14,15]}$ Furthermore, PAN presents a two-dimensional image with no information about buccal-lingual thickness. ${ }^{[1]}$ The

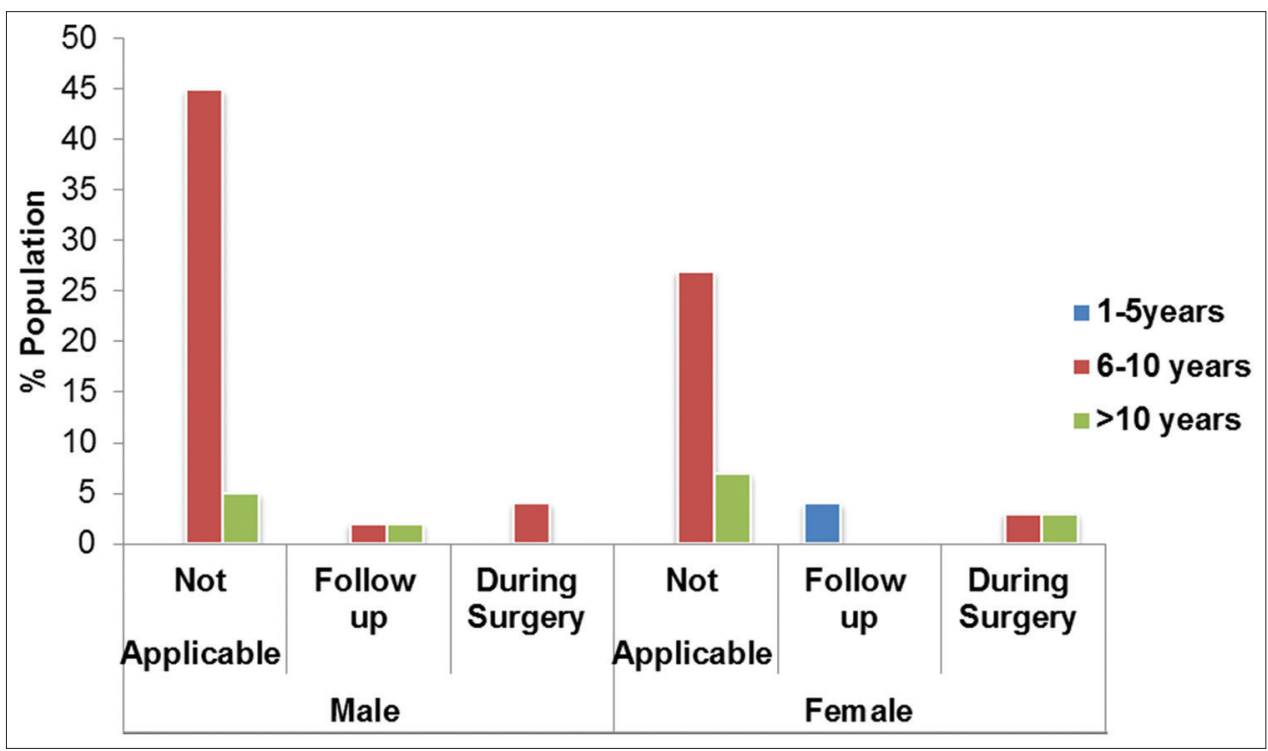

Graph 4: Gender and experience-wise \% population using periapical radiograph and the reason for its usage

Table 1: Gender and experience wise table showing problems associated with estimation of panoramic X-ray

\begin{tabular}{|c|c|c|c|c|c|c|c|c|}
\hline \multirow[t]{3}{*}{ Experience } & \multicolumn{4}{|c|}{ Male } & \multicolumn{4}{|c|}{ Female } \\
\hline & \multicolumn{2}{|c|}{ Over estmation } & \multicolumn{2}{|c|}{ Under estimation } & \multicolumn{2}{|c|}{ Over estimation } & \multicolumn{2}{|c|}{ Under estimation } \\
\hline & Yes & No & Yes & No & Yes & No & Yes & No \\
\hline $1-5$ years & & & & & 07 & 0 & 4 & 0 \\
\hline $6-10$ years & 41 & 11 & 56 & 0 & 36 & 0 & 36 & 0 \\
\hline$>10$ years & 02 & 06 & 03 & 02 & 08 & 02 & 07 & 03 \\
\hline
\end{tabular}


image magnification and the low reproducibility of alveolar canal diagnosis can increase the risks of anatomical structure damage to the inferior alveolar nerve. ${ }^{[10,13]}$

Within the limitation of smaller sample size, the present study tries to emphasize the current radiographic prescription trends in the studied population and its motivating factor.

\section{CONCLUSION}

The present study has shown that the majority of dentists sampled prescribes panoramic radiographs for dental implant assessment based on its availability and only a small number strictly adhered to the recommended guidelines of the world associations with regard to cross-sectional imaging.

\section{REFERENCES}

1. Adell R, Lekholm U, Rockler B, Brånemark PI. A 15-year study of osseointegrated implants in the treatment of the edentulous jaw. Int J Oral Surg 1981;10:387-416.

2. Albrektsson T. A multicenter report on osseointegrated oral implants. J Prosthet Dent 1988;60:75-84.

3. Andersson $\mathrm{B}$, Odman $\mathrm{P}$, Lindvall $\mathrm{AM}$, Brånemark PI. Five-year prospective study of prosthodontic and surgical single-tooth implant treatment in general practices and at a specialist clinic. Int J Prosthodont 1998;11:351-5.

4. Engelman MJ, Sorensen JA, Moy P. Optimum placement of osseointegrated implants. J Prosthet Dent 1988;59:467-73.

5. Stella JP, Tharanon W. A precise radiographic method to determine the location of the inferior alveolar canal in the posterior edentulous mandible: Implications for dental implants. Part 1: Technique. Int J Oral Maxillofac Implants 1990;5:15-22.

6. Klinge B, Petersson A, Maly P. Location of the mandibular canal: Comparison of macroscopic findings, conventional radiography, and computed tomography. Int $\mathrm{J}$ Oral
Maxillofac Implants 1989;4:327-32.

7. Lindh C, Petersson A. Radiologic examination for location of the mandibular canal: A comparison between panoramic radiography and conventional tomography. Int $J$ Oral Maxillofac Implants 1989;4:249-53.

8. Tyndall DA, Brooks SL. Selection criteria for dental implant site imaging: A position paper of the American Academy of Oral and Maxillofacial radiology. Oral Surg Oral Med Oral Pathol Oral Radiol Endod 2000;89:630-7.

9. Scaf G, Lurie AG, Mosier KM, Kantor ML, Ramsby GR, Freedman ML. Dosimetry and cost of imaging osseointegrated implants with film-based and computed tomography. Oral Surg Oral Med Oral Pathol Oral Radiol Endod 1997;83:41-8

10. Beason RC, Brooks SL. Preoperative implant site assessment in southeast Michigan. J Dent Res 2001;80:137

11. Ramakrishnan P, Shafi FM, Subhash A, Kumara A, Chakkarayan J, Vengalath J. A survey on radiographic prescription practices in dental implant assessment among dentists in Kerala, India. Oral Health Dent Manag $2014 ; 13: 826-30$

12. Peñarrocha $M$, Palomar $M$, Sanchis JM, Guarinos J, Balaguer J. Radiologic study of marginal bone loss around 108 dental implants and its relationship to smoking, implant location, and morphology. Int J Oral Maxillofac Implants 2004;19:861-7.

13. Majid IA, Ur Rahaman SM, Kumar H, Sowbhagya MB, Alikutty FK. Radiographic prescription trends in dental implant site. J Dent Implant 2014;4:140-3.

14. Reddy MS, Donahoo TM, Vanderven FJ, Jeffcoat MK. A comparison of the diagnostic advantages of panoramic radiography and computed tomography scanning for placement of root form dental implants. Clin Oral Implants Res 1994;5:229-38.

15. Bolin A, Eliasson S, von Beetzen M, Jansson L. Radiographic evaluation of mandibular posterior implant sites: Correlation between panoramic and tomographic determinations. Clin Oral Implants Res 1996;7:354-9. 